\title{
PERAN PENGETAHUAN, LOCUS OF CONTROL DAN SIKAP TERHADAP PERILAKU PETANI BAWANG MERAH DALAM PENGENDALIAN HAMA DI KABUPATEN SIGI
}

\section{COGNITION ROLE, LOCUS OF CONTROL AND MANNER TOWARDS ONION FARMER BEHAVIOUR ON PEST CONTROLLING IN SIGI DISTRICT}

\author{
Kasman Jaya $^{1^{*}}$ \\ ${ }^{1}$ Program Studi Agroteknologi, Fakultas Pertanian, Universitas Alkhairaat, Jl. Diponegoro No. 39, \\ Palu Sulawesi Tengah 94221, Indonesia
}

\begin{abstract}
ABSTRAK
Peran petani bawang merah di Kabupaten Sigi Propinsi Sulawesi Tengah sebagai pelaku utama dalam mengelolah sumber daya alam sangat menentukan keberlanjutan pertanian pada masa yang akan datang. Oleh karena itu, perilaku petani dalam pengendalian hama perlu ditingkatkan dan dilakukan pembinaan serta perlu mengkaji faktor-faktor yang mempengaruhinya. Penelitian ini bertujuan untuk mempelajari pengaruh secara langsung peran pengetahuan, locus of control, dan sikap terhadap perilaku petani dalam pengendalian hama di lahan pertanaman bawang merah di Kabupaten Sigi. Untuk menjawab tujuan yang telah dibangun, dilakukan serangkain tahapan yang merupakan satu kesatuan dari tahapan yang ditempuh merupakan proses yang sistimatis untuk mencapai tujuan. Penelitian ini merupakan penelitian survei dan ex-post fakto yang bersifat korelasional. Responden dalam penelitian ini adalah petani bawang merah di kecamatan Sigi Biromaru Kabupaten Sigi sebanyak 200 petani yang diperoleh dengan prinsip simple proporsional sampling. Data primer diperoleh dari instrument berupa; a. Kuesioner (Questionair) b. Test c. Observasi (Observation) dan d. Wawancara mendalam (In-Depth Interview). Instrumen Penelitian yang akan digunakan terlebih dahulu diuji validitas dan reliabilitasnya. Analisis deskriptif digunakan untuk menyajikan data,ukuran data, ukuran sentral, serta ukuran penyebaran. Analisis inferensial digunakan untuk menguji hipotesis dengan memakai analisis jalur (path analysis). Hasil penelitian membuktikan bahwa pengetahuan petani tentang pengendalian hama terpadu (PHT) berpengaruh langsung positif dan signifikan terhadap perilaku petani dalam melakukan pengendalian yang sesuai prinsip-prinsip PHT. Locus of control berpengaruh langsung positif dan signifikan terhadap perilaku petani dalam melakukan pengendalian yang sesuai prinsip-prinsip PHT.Pengetahuan petani tentang pengendalian hama secara terpadu dan locus of control berpengaruh positif pada sikap petani di desa Oloboju. Pengetahuan petani tentang PHT, locus of control dan sikap berpengaruh positif terhadap perilaku petani dalam pengendalian hama. Pengetahuan petani tentang PHT dan locus of control berpengaruh secara tidak langsung melalui sikap petani terhadap perilaku petani dalam PHT. Hal ini berarti peningkatan pengetahuan petani tentang PHT dan locus of control melalui sikap petani akan mendorong terjadinya perubahan perilaku petani dalam melakukan pengendalian hama secara bijaksana dan berkesesuain dengan prinsip-prinsip PHT.
\end{abstract}

Katakunci: pengetahuan, locus of control, perilaku petani, pengendalian hama.

\begin{abstract}
Onion farmers role in Sigi central Celebes as the main actor to maintain the natural resource is much determining the sustainability of future agriculture. Therefore, the farmer behavior on pest controlling is need to be improved and developed, also about the factors impacted. This study is aim to learn direct effect of locus of control and the manner towards onion farmer behavior on pest controlling in Sigi. To answer the purpose that has been told previously, we are going to do several step which is integrated to one another and systematic to gain the aim. This research is a kind of survey research and correlation ex-post facto. Respondents is the onion farmers in Sigi Biromaru as 200 farmers which obtain by proportional simple sampling principle. Primer data is obtained by several instrument such as; a). queisioner, $b$ ). test, $c$ ). observation, and d).in- depth interview. The first instrument used would be validity
\end{abstract}


and reliability test. Description analysis is used to serve the data, size data, size central, and also dissemination size. Inferential analysis is used to examine the hypothesis with path analysis. The result of the study prove that farmer cognition about Integrated Pest Controlling (IPC) positively impact and significantly towards farmer behavior on pest controlling using IPC principle. Locus of control positively directly effect and significantly towards farmer behavior on pest controlling using IPC principle. Farmer cognition about integrated pest controlling and locus of control positively effect to farmer manner in Oloboju village. Farmer cognition about IPC, locus of control, and manner positively effect towards the farmer behavior on pest controlling. Farmer cognition and locus of control indirectly effect through farmer manner toward farmer behavior on IPC. This means the proliferation of farmer cognition about $I P C$ and locus of control through farmer manner would triggered a change of farmer behavior on pest controlling and appropriate to IPC principle

Keywords: cognition, locus of control, farmer behaviour, pest controlling.

\section{Pendahuluan}

Perlindungan tanaman merupakan bagian penting dari program intensifikasi pertanian, sejalan dengan makin meningkatnya tingkat serangan hama dan penyakit atau Organisme Pengganggu Tanaman (OPT). Salah satu komoditas andalan di Propinsi Sulawesi Tengah yang mengalami kendala dalam budidaya karena tingginya serangan OPT adalah tanaman bawang merah lokal Palu. Tanaman ini merupakan bahan baku bawang goreng Palu yang banyak diminati turis lokal yang datang ke Sulawesi Tengah, karena rasanya yang gurih dan renyah. Kehilangan hasil tanaman bawang merah akibat OPT di Sulawesi Tengah bisa mencapai $30 \%$ hingga $50 \%$ bahkan beberapa daerah dilaporkan gagal panen (BP4, 2015). Badan Perlindungan Pertanian, Perkebunan dan Peternakan (BP4) Sulawesi Tengah (2015) melaporkan bahwa OPT yang umum menyerang tanaman bawang merah di Sulawesi Tengah adalah Ulat Bawang (Spodoptera exiqua), Ulat Grayak (Spodoptera litura), Trips Bawang (Trips tabaci Lind), Penyakit bercak ungu (Alternaria porii) dan Oidium spp (Embun Tepung).

Kehilangan hasil yang cukup besar akibat serangan OPT tersebut menyebabkan petani bawang merah menyandarkan pengendalian OPT pada penggunaan pestisida semata (Kasman Jaya, 2011). Hampir dipastikan bagi petani, pestisida adalah "dewa penolong" bila terjadi serangan OPT. Penggunaan pestisida diyakini petani, ampuh untuk mengatasi serangan hama dan penyakit tanaman (Suharjono, 2011; Uluwole, et al., 2009, Luluk.S., dkk. 2008; Ameriana, 2008).

\footnotetext{
${ }^{*}$ Penulis Korespondensi

E-mail: kasmanjsaad@yahoo.co.id

Telp: +62-81341025931
}

Ketergantungan petani bawang merah pada pestisida dalam pengendalian hama tentu memprihatinkan, karena menyebabkan kearifan lokal dalam pengendalian hama menjadi pudar. Menurut Khudori (2012) bahwa pertanian dengan revolusi hijau yang menekankan pada padat teknologi yaitu penggunaan benih unggul, pestisida dan pemupukan sintesis telah menyebabkan kearifan lokal petani menjadi hilang. Fenomena tersebut, terjadi pula pada petani bawang merah di kabupaten Sigi, yang merupakan sentra penghasil bawang merah di propinsi Sulawesi Tengah dalam pengendalian OPT. Faktor penting yang mempengaruhi petani dalam pengendalian OPT di Kabupaten Sigi adalah perilaku yang dipengaruhi adanya internal conflic antara pemenuhan kebutuhan dan kendala usahanya akibat gangguan hama yang hebat dan orientasi petani bawang merah masih sebatas produksi tanpa mempertimbangkan aspek keselamatan lingkungan. Aspek kepribadian seperti locus of control adalah salah satu faktor yang berpengaruh pada munculnya sikap dan perilaku petani dalam melakukan pengendalian hama. Oleh karena itu, perilaku petani dalam pengendalian hama yang berbasis ekosistem perlu ditingkatkan dan dilakukan pembinaan. Pengetahun petani bawang merah di Kabupaten Sigi sebagai pelaku utama dalam mengelolah sumber daya alam perlu ditingkatkan guna keberlanjutan pertanian pada masa yang akan datang (Kasman Jaya et al, 2015).

Berdasarkan hal tersebut diatas maka untuk meningkatkan perilaku petani bawang merah dalam pengendalian hama tanaman perlu mengkaji faktor-faktor yang mempengaruhinya. Pengendalian hama tanaman yang berbasis ekosistem adalah bentuk pengendalian hama yang menekankan pada aspek ekosistem lokal daripada intervensi teknologi dan petani sudah ditempatkan sebagai subyek atau penentu 


\section{Jurnal Oazrotech 8 (1) 1-7}

keputusan kegiatan pengendalian hama atau sebagai ahli PHT (Oka,1998). Peran petani di Kabupaten Sigi sebagai pelaku utama dalam mengelola sumber daya alam dan lingkungan sangat menentukan keberlanjutan pertanian pada masa yang akan datang. Perilaku berwawasan lingkungan petani perlu ditingkatkan dan dilakukan pembinaan. Peningkatan perilaku petani dalam pengendalian hama yang sesuai dengan prinsip-prinsip PHT akan menekan dampak negatif penggunaan pestisida terhadap lingkungan. Penelitian ini bertujuan untuk mengetahui gambaran pengetahuan tentang PHT, locos of control dan sikap petani tentang PHT dan perilaku petani dalam pengendalian hama tanaman bawang merah di Kabupaten Sigi, dan mempelajari pengaruh secara langsung peran pengetahuan tentang PHT dan locus of control petani terhadap sikap petani dalam pengendalian hama tanaman bawang merah di Kabupaten Sigi, serta mempelajari pengaruh secara langsung peran pengetahuan tentang PHT dan locus of control petani dan sikap terhadap perilaku petani dalam pengendalian hama tanaman bawang merah di Kabupaten Sigi.

\section{Metode Penelitian}

Penelitian ini dilaksanakan di desa Olobojo dan desa Soulowe Kecamatan Sigi Biromaru Kabupaten Sigi Propinsi Sulawesi Tengah selama enam bulan, yaitu mulai Agustus 2016 sampai Februari 2017. Sasaran penelitian adalah petani bawang merah di kabupaten Sigi.

Populasi dalam penelitian adalah petani pemilik yang mengolah dan menanam bawang merah di Kabupaten Sigi. Sedangkan Populasi yang terjangkau adalah petani di desa Olobojo dan desa Soulowe yang merupakan sentra bawang merah di Kabupaten Sigi. Penentuan sampel dengan memilih 200 petani dengan metode probability sample dengan prinsip simple proporsional sampling, sampel seluruhnya 200 petani bawang merah.

Penelitian menggunakan metode kausal dengan analisis multivariate dengan analisis jalur (Path analysis). Sesuai dengan tujuan penelitian yang telah dibuat, maka penelitian ini menggunakan pola eksplanasi (level of explanation) yaitu penelitian yang dimaksudkan untuk menjelaskan kedudukan variabel-variabel yang diteliti serta hubungan antara satu variabel dengan variabel lain. Dengan demikian penelitian ini menjelaskan pengaruh variabel pengetahuan tentang PHT, locus of control, sikap
e-ISSN : 2621-7236

p-ISSN : 1858-134X

petani terhadap perilaku petani bawang merah dalam pengendalian hama. Berdasarkan hubungan veriabel merupakan penelitian korelasional, serta berdasarkan data yang dikumpulkan merupakan penelitian ex post facto. Unit analisis yang dipergunakan dalam penelitian ini adalah individu (petani terjangkau). Individu yang dimaksud disini adalah petani bawang merah di Kecamatan Sigi Biromaru Kabupaten Sigi.

Desain penelitian merupakan rencana dan struktur penelitian yang dibuat sedemikian rupa agar diperoleh jawaban atas pertanyaan penelitian. Pada penelitian ini semua variabel yang ada dianggap homogen, dimana variabel konstruk eksogen/independen yang digunakan mempunyai hubungan secara langsung maupun tidak langsung terhadap variabel konstruk endogen/dependen, hubungan tidak langsung terjadi karena terdapat variabel independen yaitu; variabel antara (Y1) yaitu sikap yang harus dilalui sebelum mencapai variabel dependent (Y2) yaitu perilaku petani dalam pengendalian hama.

Berdasarkan analisis data yang digunakan, maka dalam penelitian ini dikelompokan menjadi dua, yaitu teknik analisis statistik deskriptif dan teknik analisis statistik inferensial. Teknik analisis statistik deskriptif digunakan untuk menggambarkan karakteristik masing-masing responden penelitian. Dalam analisis ini menggunakan informasi tentang mean (rata-rata), distribusi frekuensi dan persentase yang disajikan dalam bentuk tabel.

Analisis statistik inferensial yang digunakan untuk menguji pengaruh langsung variabel pengetahuan tentang pengendalian hama Locus Of Control dan pengaruh tidak langsung variabel pengetahuan pengendalian hama dan Locus Of Control terhadap perilaku petani dalam pengendalian hama serta pengaruh sikap terhadap perilaku petani dalam pengendalian hama.

Analisis jalur (path analysis) yang didahului dengan uji normalitas serta uji homogenitas varians. Pengaruh langsung dan tidak langsung variabel eksogen (variabel independen) terhadap suatu variabel endogen (variabel dependen) dapat diketahui dengan melihat koefisien jalur. Persyaratan analisis dan uji linearitas yang digunakan adalah uji normalitas dan uji homogenitas varians. Normalitas data menggunakan uji Kolmogorov Smirnov, sedangkan homogenitas varians menggunakan uji Bartlett dan uji linearitas dilakukan dengan menggunakan uji anova (Uji F) 


\section{Hasil dan Pembahasan}

Berdasarkan model analisis jalur (Path analysis) yang dijadikan sebagai acuan dari
p-ISSN : 1858-134X

analisis penelitian ini diketahui terdapat empat pengaruh langsung positif, adalah sebagai berikut:

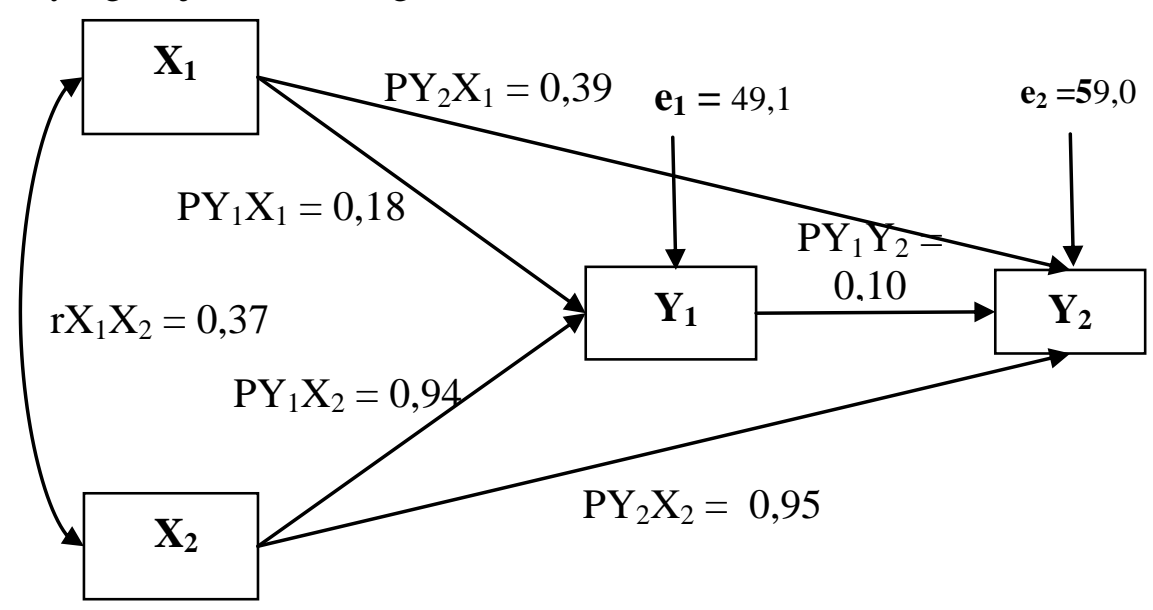

Gambar 1. Model analisis jalur penelitian

Temuan penelitian menunjukkan bahwa pengetahuan pengendalian hama berpengaruh positif dan signifikan terhadap buruk tidaknya perilaku petani dalam pengendalian hama. Artinya perilaku petani yang baik dalam pengendalian hama yaitu yang sesuai dengan prinsip pengendalian hama terpadu, meskipun menggunakan pestisida namun dilaksanakan secara bijak sana. Prinsip-prinsip PHT menurut Untung (2006) adalah; 1). Dilaksanakannya tehnik budidaya tanaman sehat, 2). Dilaksanakan pengendalian secara hayati atau musuh alami, 3). Dilakukan pemantauan ekosistem secara teratur, dan 4). Petani sebagai penentu keputusan pengendalian atau sebagai ahli PHT.

Besarnya kontribusi pengetahuan yang secara langsung berkontribusi terhadap perilaku petani dalam pengendalian hama secara baik dan benar sebesar $3,90 \%$. Olehnya karena itu untuk memperbaiki perilaku petani dalam pengendalian hama yang sesuai prinsip PHT harus diupayakan dengan peningkatan pengetahuan petani tentang PHT. Hal ini sejalan dengan pendapat Hines et al. (1986), menyatakan bahwa pentingnya faktor pengetahuan yaitu pengetahuan tentang aksi dan isu, keterampilan bertindak, keinginan bertindak, faktor-faktor situasional dan faktor kepribadian dalam merubah perilaku. Hal yang sama dikemukan oleh Robbins (2003), bahwa faktor yang mendorong seseorang berperilaku disebabkan oleh empat aspek yaitu adanya pengetahuan, persepsi, sikap dan nilai dari suatu obyek. Seseorang berperilaku atau beraktivitas karena kebutuhan untuk suatu tujuan. Perilaku terjadi karena dorongan dari dalam diri seseorang.

Model perubahan perilaku dikemukan oleh Ajzen (1991), lebih menjelaskan bahwa perubahan perilaku sangat ditentukan oleh sikap (attitudes), pengetahuan (knowledge), pengaruh (self-efficacy), tempat (locus of control), dan maksud (intent). Suatu perilaku tidak terbentuk begitu saja tanpa adanya perencanaan atau kesadaran seseorang akan tujuan yang ingin dicapai melalui perilaku tersebut. Olehnya petani bawang merah di Kabupaten Sigi harus terus diberi penguatan baik dengan bentuk peningkatan pengetahuan lewat SLPHT atau penyuluhanpenyuluhan tentang pengendalian hama yang baik dan benar, yang sesuai dengan prinsip PHT. Bloom (1979) menjelaskan bahwa dalam memahami terjadinya perubahan perilaku, yang dimulai dengan proses belajar dalam memperoleh pengetahuan (Knowledge). Setelah pengetahuan diperoleh, maka seseorang akan tersimpan dalam dirinya pengetahuan tersebut, sehingga membentuk sikap (Attitude), yang selanjutnya bertindak (Practic), sebagai bentuk tingkah laku atau perilaku. Sejalan dengan itu Ameriana (2008) dalam penelitiannya menunjukan adanya pengaruh pengetahuan terhadap petani dalam penggunaan pestisida dalam tanaman sayur. Selanjutnya disimpulkan bahwa semakin rendah pengetahuan petani semakin tinggi kuantitas pestisida yang digunakan.

Selanjutnya, temuan penelitian menunjukkan bahwa locus of control berpengaruh positif dan signifikan terhadap perilaku petani dalam pengendalian hama. 


\section{Jurnal Agrotech 8 (1) 1-7}

Artinya baik dan benarnya petani dalam pengendalian hama dijelaskan oleh locus of control yang dimilikinya. Besarnya locus of control yang secara langsung berkontribusi terhadap perilaku petani dalam pengendalian hama sebesar 9,50\%. Oleh karena itu untuk mengoptimalkan peran petani dalam pengendalian hama yang baik harus diupayakan peningkatan locus of control. Temuan dalam penelitian diperkuat pernyataan Vaughan dan Michael Hogg (1995) yang menyatakan bahwa manusia mempunyai perbedaan dalam cara memandang dirinya. Hal ini bergantung pada besarnya kontrol yang dirasakan sebagai penguatan dan hukuman yang diterimanya. Menurut Rasmita $d k k$ (2009) seseorang dengan locus of control (kepercayaan diri) yang tinggi akan mampu memainkan peran dalam efektifitas kinerjanya dan memberi kebermaknaan bagi diri sendiri dan orang lain. James L. Gibson dalam Rasmita $d k k$ (2009) menyebut locus of control sejauh mana keyakinan seseorang bahwa pada dasarnya mereka otonom dalam bekerja, dalam kaitanya dengan pengendalian hama petani menentukan sendiri secara otonom tehnik pengendalian hama yang ingin digunakan tanpa harus diintervensi oleh pihak manapun. Jadi seseorang akan menentukan pilihannya dan percaya sepenuhnya kontrol terhadap dirinya akan terjadi pada dirinya sendiri dan itu menjadi tanggung jawabnya atas segala pilihannya. Olehnya untuk memberikan hasil yang baik dan tidak memberi dampak buruk bagi lingkungan, maka perlu penguatan kepada petani tentang dampak samping penggunaan pengendalian pestisida yang secara berlebihan.

Rotter dalam Rasmita $d k k$ (2009) menyebut locus of control sebagai tingkatan kepercayaan seseorang terhadap tindakantindakan yang mempengaruhi hasil-hasilnya, rewards, dan penguatan-penguatan yang dihasilkanya, di dalam kehidupan sehari-hari apakah dipandang karena tindakan sendiri (internal locus of control) atau karena faktor lingkungan yang tidak dapat dikontrol (externallocus of control). Jadi seseorang yang percaya bahwa sesuatu peristiwa terjadi di dalam hidupnya oleh karena akibat hasil perilaku tindakannya atau kemampuannya, personalitas dan upayanya dikatakan bahwa ia memiliki kapasitas harapan kontrol internal, sedangkan seseorang yang percaya bahwa suatu peristiwa di dalam hidupnya adalah karena fungsi dari faktor keuntungan, kesempatan, dan nasib atau kekuatan lainnya diluar kontrol dirinya dikatakan orang
e-ISSN : 2621-7236

p-ISSN : 1858-134X

tersebut memiliki kapasitas harapan kontrol eksternal.

Kuatnya locos of control dalam penelitian ini menyebabkan perilaku petani dalam pengendalian hama menjadi penting untuk diperhatikan dan ditumbuh sadarkan kepada petani bawang merah agar lebih bijak dalam menggunakan pengendalian dengan pestisida. Locus of control merupakan karakteristik personalitas yang mengacu kepada sampai seberapa jauh seseorang memiliki keyakinan bahwa peristiwa-peristiwa yang terjadi adalah berada di dalam kontrol dirinya, termasuk dalam menentukan pilihan dalam pengendalian hama yang tepat dan bijakasana.

Temuan penelitian juga menunjukkan bahwa terdapat pengaruh positif dan signifikan sikap dengan perilaku petani dalam pengendalian hama. Artinya petani dengan sikap positif terhadap PHT, cenderung akan berpartisipasi dan perilaku positif terhadap PHT. Sikap dan perilaku sering dikatakan berkaitan erat, seperti yang dikemukakan oleh Taylor et al (2012) mengungkapkan bahwa relasi antara sikap dan perilaku bisa bersifat timbal balik. Sikap mungkin mengontrol perilaku, dan perilaku terkadang mengotrol sikap. Mueller dalam Venus (2004) medefinisikan sikap sebagai kecenderungan untuk bertindak terhadap objek tertentu baik secara positif maupun negatif dengan mendasarkan diri pada keyakinankeyakinan yang teroganisasi.

Selanjutnya temuan penelitian juga menunjukkan bahwa terdapat pengaruh positif dan signifikan pengetahuan PHT, locus of control dan sikap terhadap perilaku petani dalam pengendalian hama. Hal ini ditujukkan oleh analisis eksogen terhadap endogen, baik secara menyeluruh maupun individu. Baik buruknya petani dalam pengendalian hama dipengaruhi oleh pengetahuan PHT, locus of control dan sikap. Pengaruh ketiga variabel tersebut terhadap perilaku petani dalam pengendalian hama sebesar $10 \%$. Peningkatan perilaku pengendalian yang baik dan benar dapat dilakukan dengan peningkatan pengetahuan tentang pengendalian hama dan locus of control petani, baik secara menyeluruh maupun secara individu. Pemerintah, khususnya dinas peratanian beserta infrastrukturnya, seharusnya lebih berperan untuk meningkatkan pengetahuan petani dengan berbagai bentuk kegiatan pelatihan, sosialisasi atau sekolah lapang (SLPHT) yang tidak hanya sekedar menunaikan proyek, tetapi secara kontinu dan berintegritas. 


\section{Jurnal Agrotech 8 (1) 1-7}

Secara keseluruhan temuan penelitian menunjukkan bahwa analisis model perilaku petani dalam pengendalian hama dipengaruhi secara langsung oleh pengetahuan PHT, locus of control dan sikap petani tentang PHT. Demikian pula perilaku petani dalam pengendalian hama dipengaruhi secara tidak langsung oleh pengetahuan PHT dan locus of control melalui sikap. Hal ini dapat dijelaskan bahwa pengetahuan PHT petani dan locus of control yang tinggi dimiliki oleh petani didorong oleh adanya sikap yang positif petani terhadap PHT, maka akan berkontribusi kepada peningkatan kualitas perilaku petani dalam melakukan pengendalian hama. Menurut Suhardi (2013) bahwa faktor paling dominan berpengaruh terhadap perilaku petani dalam pemakaian pestisida adalah sikapnya.

Selanjutnya menurut Notoatmodjo (2007) menyebutkan bahwa pengetahuan merupakan domain yang sangat penting untuk terbentuknya perilaku seseorang. Perubahan perilaku baru adalah suatu proses yang kompleks dan memerlukan waktu yang relatif lama. Tahapan yang pertama adalah pengetahuan, sebelum seseorang mengadopsi perilaku baru harus tahu terlebih dahulu, apa arti atau manfaat perilaku tersebut. Sehingga perilaku seseorang sangat dipengaruhi oleh pengetahuan. Chiras (1991) menilai bahwa sepanjang sejarah, manusia menggunakan pengetahuannya untuk mengontrol lingkungan, membentuknya dan mengamankannya agar hidupnya bisa sukses dan harmonis.

\section{Kesimpulan}

Berdasarkan hasil pengujian hipotesis dan pembahasan penelitian, diperoleh temuan penelitian dan disimpulkan sebagai berikut:

1. Pengetahuan petani tentang pengendalian hama terpadu (PHT) berpengaruh langsung positif dan signifikan terhadap perilaku petani dalam melakukan pengendalian yang sesuai prinsip-prinsip PHT. Hal ini berarti peningkatan pengetahuan petani tentang PHT penting dilakukan secara intensif dan kontinu.

2. Locus of control berpengaruh langsung positif dan signifikan terhadap perilaku petani dalam melakukan pengendalian yang sesuai prinsipprinsip PHT. Locus of control dalam hal ini kepercayaan harus dibangun dalam diri petani untuk lebih bijaksana dalam menggunakan pestisida dan berperilaku yang baik dan benar dalam melakukan pengendalian hama.
e-ISSN : 2621-7236

p-ISSN : 1858-134X

3. Pengetahuan petani tentang pengendalian hama secara terpadu dan locus of control berpengaruh positif pada sikap petani di desa Oloboju. Hal ini berarti peningkatan pengetahuan PHT petani dan locus of control akan menyebabkan peningkatan sikap petani dalam melakukan pengendalian yang baik dan benar yang sesuai dengan prinsip-prinsip PHT.

4. Pengetahuan petani tentang PHT, locus of control dan sikap berpengaruh positif terhadap perilaku petani dalam pengendalian hama. Hal ini berarti peningkatan pengetahuan petani tentang PHT, locus of control dan sikap petani akan menyebabkan perubahan perilaku petani dalam melakukan pengendalian hama yang lebih sesuai dengan prinsip-prinsip PHT.

5. Pengetahuan petani tentang PHT dan locus of control berpengaruh secara tidak langsung melalui sikap petani terhadap perilaku petani dalam PHT. Hal ini berarti peningkatan pengetahuan petani tentang PHT dan locus of control melalui sikap petani akan mendorong terjadinya perubahan perilaku petani dalam melakukan pengendalian hama secara bijaksana dan berkesesuain dengan prinsipprinsip PHT.

\section{Daftar Pustaka}

Ameriana, M. 2008. Perilaku Petani Sayuran Dalam Menggunakan Pestisida Kimia. Journal J. Hort. 18(1):95-106, 2008

Ajzen. 1991. The Theory of Planned Behavior Organization Behavior and human. Decision Processes

Badan Perlindungan Pertanian, perkebunan dan Peternakan Sulawesi Tengah. 2015. Laporan Tahunan Kegiatan 2014. Kabupaten Sigi: BP4

Bloom, B. 1979. Taxonomi Of Educational Objectives Book I Cognitive Domain. London: Longman Ltd.

Chiras, Daniel D. 1991. Enviromental Science. Action For A Sustainable Future. The Benjamin/Cummings Company,Inc. California.

Hinnes J.E, S.J. Johnson, \& A.D. Burt. 1986. What Does Brand Mean? HistoricalAnalysis Method and Construct Definition. Am. J.Pathol. 142:511-518 
Jurnal agrotech 8 (1) 1-7

Kasman Jaya. 2011. Ketepatan Penggunaan Pestisida di Tingkat Petani Kasus Petani Tanaman Pangan dan Hortikultura di Kecamatan Biromaru Kabupaten Sigi. Jurnal KIAT .Vol.03 N0.02 Juni 2011 No.ISSN:0216-7530 hal; 68-73. Unisa, Palu

Kasman Jaya, Muhammad Ardi, Sylvia Sjam \& Gufran D. Dirawan , 2015. Onion Farmers Behavior In Ecosystem-Based Pest (EBP) Control In Sigi District Of Central Sulawesi Province. Journal Man In India, 95 (3):649-659 @Serial Publication.

Khudori. 2012. Neoliberalisme Menumpas Petani. Yogyakarta: Resist Book

Luluk. S., Rudy C.R., Bunasor Sanim \& Dadang, 2008. Pengetahuan Sikap dan Tindakan Petani Bawang Merah dalam Penggunaan Pestisida. Jurnal J.Agroland 15 (1):12-17 .

Notoatmodjo, S. 2007. Promosi Kesehatan Teori dan Ilmu Perilaku. Jakarta: Rineka Cipta.

Oka.,I.B. 1998. Pengendalian Hama Terpadu dan Implementasinya di Indonesia. Yogyakarta: Gadjah Mada University Press.

Rasmita, Elfindri, Wello dan Rumengan., 2009. Pintar Soft Skills, Membentuk Pribadi Unggul. Penerbit Baduose Media, Jakarta.
e-ISSN : 2621-7236

p-ISSN : 1858-134X

Robbins, S. P., 2003. Essentials of Organizational Behavior, $7^{\text {th }}$ edition, New Jersey: Pearson Education Inc.

Suhardi. 2013. Faktor-Faktor yang Berpengaruh pada Perilaku Pemakaian Insektisida; Studi Kasus Petani Bawang Merah Di Kelurahan Tanjung Sari, Kecamatan Wanasari. Tesis. UI Jakarta

Suharjono, 2011. Dampak Implementasi Sekolah Lapang Pengendalian Hama Terpadu (SLPHT) Padi Terhadap Penggunaan Pestisida. Jurnal Agrovigor. Vol. 4 No.1.

Taylor, S.E., Peplau, L.A \& Sears. D.O. 2012. Social Psychology. 12 th Edition. Prentice hall. Pearson Education, Inc

Untung, K. 2006. Pengantar Pengelolaan Hama Terpadu. Gadjah Mada Yogyakarta : University Press

Uluwole, Oluwafemi, Cheke \& Robert, 2009. Health and Enviromental Impact of Pesticide Use Practices: A Case Study Of Farmers in Eki State, Nigeria. International Journal of Agriculture Sustainability Vol 7, No.3; pp 153-163.

Vaughan, G. Dan Michael Hogg. 1995. Introduction so Social Psychology. Prentice Hall. Sydney.

Venus, Antar, 2009. Manejemen Kampanye. Simbiosa Rekatama Media, Bandung 